\title{
Sex, susceptibility to smoking and chronic obstructive pulmonary disease: the effect of different diagnostic criteria. Analysis of the Health Survey for England
}

\author{
Rachel E Jordan, ${ }^{1}$ Martin R Miller, ${ }^{2}$ Kin-bong Hubert Lam, ${ }^{2} \mathrm{~K}$ K Cheng, ${ }^{1}$ Jennifer Marsh, \\ Peymané Adab ${ }^{1}$
}

'Public Health, Epidemiology and Biostatistics, University of Birmingham, Birmingham, UK ${ }^{2}$ Institute of Occupational and Environmental Medicine, University of Birmingham, Birmingham, UK

\section{Correspondence to}

Dr R E Jordan, Public Health, Epidemiology and Biostatistics, School of Health and Population Sciences, Public Health Building, University of Birmingham, B15 2TT, UK;

r.e.jordan@bham.ac.uk

Received 18 November 2011 Accepted 2 February 2012 Published Online First 1 March 2012

\section{ABSTRACT}

Background Some previous studies suggest there are sex differences in susceptibility to, and prevalence of, chronic obstructive pulmonary disease (COPD) but findings are inconsistent. In this study, whether different diagnostic criteria for COPD may contribute to these conflicting findings was examined.

Methods Cross sectional analysis of data from the 1995, 1996 and 2001 Health Survey for England was undertaken, including participants of white ethnicity, aged $40+$ years with a valid smoking history and lung function data. COPD was defined using Global Initiative for Chronic Obstructive Lung Disease (GOLD), National Institute for Health and Clinical Excellence (NICE) and lower limit of normal (LLN) spirometric criteria, in the absence of a diagnosis of asthma.

Results COPD was present in 3035 (16.1\%), 1304

(7.0\%) and 1684 (9.0\%) people, according to the GOLD, NICE and LLN criteria, respectively. With both the GOLD and NICE definitions, men had significant independent increased risks of COPD compared with women (OR 1.46 (95\% Cl 1.34 to 1.59 ) and 1.30 (1.15 to 1.48 ), respectively). With the LLN definition, this effect was removed (OR 0.96 (0.87 to 1.07). With the use of both the GOLD and NICE criteria, women had significantly greater susceptibility to COPD (25-30\% higher risk) for the same level of pack years of exposure. This was not observed with the LLN criteria.

Conclusions The study indicates that sex differences in risk of COPD reported in previous studies are influenced by the definition used for COPD. When using a statistically driven definition (LLN), no independent sex difference was found and there was no evidence of an increased susceptibility to COPD among female compared with male smokers.

\section{INTRODUCTION}

Chronic obstructive pulmonary disease (COPD) is a respiratory disease of heterogeneous nature with an increasing burden worldwide. ${ }^{1}$ It is characterised by a progressive decline in lung function. Smoking is the most important risk factor, contributing over $70 \%$ of the total disease burden in high income countries, although less in lower income countries. ${ }^{1}$

Traditionally COPD has been seen as a disease predominantly affecting men, mainly a result of their higher prevalence of smoking historically. However, with female smoking rates in the developed world now almost comparable with those of men, ${ }^{2}$ COPD prevalence among women has

\section{Key messages}

What is the key question?

- Does the choice of diagnostic criteria affect the relationships between sex, susceptibility to smoking and chronic obstructive pulmonary disease (COPD)?

\section{What is the bottom line?}

- Use of the Global Initiative for Chronic Obstructive Lung Disease (GOLD) and National Institute for Health and Clinical Excellence (NICE) criteria results in apparent associations between sex and risk of COPD, and sex differences in susceptibility to smoking, not observed with the lower limit of normal criteria.

\section{Why read on?}

- Choice of disease definition is critical in the interpretation of epidemiological studies. Our findings suggest that the definition of COPD used needs to be considered before drawing inferences about observed associations, particularly when the risk factor being considered differs by sex.

risen, ${ }^{3}{ }^{4}$ and the incidence of COPD may now be higher in younger women. ${ }^{5}$ Furthermore, although the debate remains controversial, ${ }^{6}$ it has been shown in some studies that women who smoke have significantly higher risks of tobacco related diseases than men and an important recently published meta-analysis demonstrated a $25 \%$ increased risk of coronary heart disease among female compared with male smokers. ${ }^{7}$ However, in relation to COPD, the results of relevant studies are not consistent.

A recent systematic review of 11 population based cohort studies ${ }^{8}$ reported a significantly faster decline in lung function (measured by forced expiratory volume in $1 \mathrm{~s}\left(\mathrm{FEV}_{1}\right)$ expressed as per cent predicted/year) among smoking women compared with men, although there was significant heterogeneity between studies. Two further cohort studies showed non-significant increased risks of COPD hospitalisation among women for a given number of pack years, ${ }^{9}$ and in another cohort ${ }^{10}$ the incidence of COPD among those with respiratory symptoms was greater (although again not 
significantly) for female smokers compared with their male counterparts. In contrast, a meta-analysis of eight cross sectional studies showed no evidence of significant sex differences in the age, height and race adjusted effects of smoking on absolute $\mathrm{FEV}_{1}{ }^{11}$ while conversely an analysis of the Framingham Offspring Cohort ${ }^{12}$ reported that male smokers had a small but significantly increased rate of $\mathrm{FEV}_{1}$ decline.

One potential explanation for the conflicting results is the known controversy over the use of a simple fixed $\mathrm{FEV}_{1} /$ forced vital capacity (FVC) ratio to confirm a diagnosis of COPD (Global Initiative for Chronic Obstructive Lung Disease (GOLD) definition) or the additional use of a threshold for per cent of predicted $\mathrm{FEV}_{1}$ values to define lung function impairment (recommended by the National Institute for Health and Clinical Excellence (NICE)). Both of these criteria have been shown to overestimate COPD with increasing age, particularly among men, compared with statistical approaches such as the lower limit of normal (LLN). ${ }^{13}$

In this analysis, we used 3 years of data from the Health Survey for England (HSE) to examine how the criteria used to diagnose COPD affects the relationship between sex and COPD and whether there is any evidence of increased susceptibility among women to cigarette smoke.

\section{METHODS}

\section{Study design}

This was a cross sectional analysis of data collected by the annual HSE in 1995, 1996 and 2001, to establish the associations between sex, susceptibility to smoking and risk of COPD and quantifying the effects of each when using different diagnostic criteria.

\section{Setting: Health Survey for England}

The HSE is part of a set of annual surveys designed to monitor the health of the nation. The dataset is publicly available. Briefly, a general population sample was surveyed each year, obtained by multistage stratified random sampling of private households in England. ${ }^{14-16}$ Home interviews and health assessments by trained interviewers and nurses were carried out for over 15000 adults each year. In 1995, 1996 and 2001, information on respiratory health was additionally collected, as was an assessment of lung function $\left(\mathrm{FEV}_{1}, \mathrm{FVC}\right.$ and peak expiratory flow). Data were obtained from the UK data archive. ${ }^{17}$ Data from all 3 years were combined, reflecting the identical sampling and survey design.

\section{Participants}

Participants of white ethnicity, aged 40 years and above and with valid lung function tests and height data were included in this analysis. Because there was no reversibility testing done as part of the study, in order to reduce misclassification of COPD, any participants reporting physician diagnosed asthma were excluded.

\section{Questionnaire and procedures}

All consenting participants received a standard computer assisted interview, including information on demographic characteristics, smoking history, ethnicity, occupation and educational level. Participants were specifically asked if they had ever been diagnosed with asthma, and if they had any (and which) longstanding illnesses. Socioeconomic status was grouped into non-manual occupations and manual/other occupations. Smoking habit was defined as current, ex- and never regular smokers (where regular was defined as at least 1 cigarette per day). Pack years were calculated for all participants.
Pulmonary function tests were performed according to a standard protocol ${ }^{14-16}$ with a Vitalograph Escort spirometer (Fleisch pneumotachograph flow head) which was calibrated daily with a 11 syringe at normal room temperature. At the participant's house, room temperature was first recorded and entered. Five blows were attempted in the standing position unless the patient was chairbound, and noted whether technically acceptable or not. The best $\mathrm{FEV}_{1}$ and FVC measures were used. No reversibility tests were performed and bronchodilators were not used. Patients who were pregnant, or who had abdominal or chest surgery in the preceding 3 weeks, or who had been admitted to hospital with a heart complaint in the previous 6 weeks were excluded.

\section{Outcomes}

The main outcome measure was the presence of COPD (measured by the presence of airflow obstruction), comparing three different spirometric criteria for defining obstructive airways disease:

1. GOLD criteria ${ }^{18}: \mathrm{FEV}_{1} / \mathrm{FVC}$ ratio $<0.7$

2. NICE criteria: $\mathrm{FEV}_{1} / \mathrm{FVC}<0.7$ and $\mathrm{FEV}_{1}<80 \%$ predicted (equivalent to GOLD stage II) ${ }^{19}$

3. LLN criteria: defined using the reference equations from the European Community for Steel and Coal Study. ${ }^{20}{ }^{21}$ In this way, participants were classified as having obstructive airways disease if their pre-bronchodilator $\mathrm{FEV}_{1} / \mathrm{FVC}$ values were below the lowest $5 \%$ of the frequency distribution of values found in the healthy reference population.

\section{Statistical analysis}

Logistic regressions on risk of COPD with each of the three criteria, adjusting for age, sex, pack years smoked and socioeconomic status, were undertaken in STATA V.11.0 (table 2). These models were then extended by adding an interaction term for sex and amount smoked (table 3).

\section{RESULTS}

\section{Study participants}

In the combined 1995, 1996 and 2001 dataset, of 27653 white British participants aged 40 years and over, 2989 (10.8\%) reported physician diagnosed asthma, and of the remainder, 18817 (76.3\%) provided valid lung function tests with reliable height measures.

Table 1 describes the baseline characteristics of the included participants. Overall, 8892 (47.3\%) of the participants were men and mean age was 58.1 years (SD12.2). A total of 4259 $(22.6 \%)$ participants were current smokers although 7951 (42.3\%) had never smoked regularly. Most smokers had smoked $<50$ pack years. A total of 7984 (42.4\%) participants reported a manual occupation while 10525 (55.9\%) reported non-manual occupations.

COPD was present in 3035 (16.1\%), 1304 (7.0\%) and 1684 (9.0\%) participants according to the GOLD, NICE and LLN criteria, respectively. The age, sex and socioeconomic profiles were similar across the 3 years although in 2001 there were fewer current and ever smokers, a lower prevalence of airflow obstruction and fewer participants reporting respiratory conditions.

\section{Association between sex, smoking and COPD}

Table 2 shows the relationship between age, sex, smoking and risk of COPD for each of the three different definitions of COPD within the combined dataset. For each definition, COPD increased significantly with age although this was significantly 
Table 1 Characteristics of the included patients

\begin{tabular}{|c|c|c|c|c|}
\hline & 1995 & 1996 & 2001 & All \\
\hline $\mathrm{N}$ & 6379 & 6771 & 5667 & 18817 \\
\hline Men (n (\%)) & $3033(47.6)$ & $3197(47.3)$ & $2662(47.0)$ & $8892(47.3)$ \\
\hline Age (years) (mean (SD)) & $58.4(12.3)$ & $58.1(12.3)$ & $58.0(12.0)$ & $58.1(12.2)$ \\
\hline $40-49$ & $1916(31.0)$ & $2168(32.0)$ & $1634(28.8)$ & $5718(30.4)$ \\
\hline $50-59$ & $1635(25.6)$ & $1677(24.8)$ & $1705(30.1)$ & $5017(26.7)$ \\
\hline $60-69$ & $1437(22.5)$ & $1504(22.2)$ & $1196(21.1)$ & $4137(22.0)$ \\
\hline \multicolumn{5}{|l|}{ Smoking status (n (\%)) } \\
\hline Never regular & $2635(41.3)$ & $2811(41.5)$ & $2505(44.2)$ & $7951(42.3)$ \\
\hline Ex-regular & $2287(35.9)$ & 2327 (34.4) & $1990(35.1)$ & $6604(35.1)$ \\
\hline Current & $1455(22.8)$ & $1633(24.1)$ & $1171(20.7)$ & $4259(22.6)$ \\
\hline Not reported & $2(0.03)$ & 0 & $1(0.02)$ & $3(0.02)$ \\
\hline $50+$ & $407(6.4)$ & $407(6.4)$ & $331(5.9)$ & $1151(6.1)$ \\
\hline \multicolumn{5}{|c|}{ Socioeconomic status/occupation (n (\%)) } \\
\hline Non-manual occupation & $3545(55.6)$ & $3759(55.5)$ & $3221(56.8)$ & $10525(55.9)$ \\
\hline Manual occupation & $2732(42.8)$ & $2903(42.9)$ & $2349(41.5)$ & $7984(42.4)$ \\
\hline Other & $13(0.2)$ & $16(0.2)$ & $12(0.2)$ & $41(0.2)$ \\
\hline Not reported & $89(1.4)$ & $93(1.4)$ & $85(1.5)$ & $267(1.4)$ \\
\hline \multicolumn{5}{|l|}{ Diagnosed conditions ( $\mathrm{n}(\%))$} \\
\hline Any longstanding illness & 3085 (48.4) & 3304 (48.8) & $2852(50.3)$ & $9341(49.6)$ \\
\hline Respiratory conditions & $287(4.5)$ & $268(4.0)$ & $175(3.1)$ & $730(3.9)$ \\
\hline Bronchitis/emphysema & $81(1.3)$ & $88(1.3)$ & $39(0.7)$ & $208(1.1)$ \\
\hline \multicolumn{5}{|l|}{$\mathrm{COPD}^{*}(\mathrm{n}(\%))$} \\
\hline GOLD & $1190(18.7)$ & $1087(16.1)$ & $758(13.4)$ & $3035(16.1)$ \\
\hline
\end{tabular}

${ }^{*}$ Global Initiative for Chronic Obstructive Lung Disease (GOLD) criteria ${ }^{18}$ : FEV//FVC ratio $<0.7$; National Institute for Health and Clinical Excellence (NICE) criteria: $\mathrm{FEV} / / \mathrm{FVC}<0.7$ and FEV $<80 \%$ predicted (equivalent to GOLD stage II) ${ }^{19}$; lower limit of normal (LLN) criteria ${ }^{20}{ }^{21}$ : participants with FEV $/$ /FVC values $>1.645$ SD below the mean reference value.

$\mathrm{COPD}$, chronic obstructive pulmonary disease; $\mathrm{FEV}_{1}$, forced expiratory volume in $1 \mathrm{~s}$; FVC, forced vital capacity.

more marked with the GOLD and NICE definitions compared with the LLN definition. With both the GOLD and NICE definitions, being male was associated with a significantly increased risk of having COPD (OR 1.46 (95\% CI 1.34 to 1.59) and 1.30 (1.15 to 1.48), respectively). With the LLN definition, no statistically significant difference in risk between men and women was observed (OR 0.96 (0.87 to 1.07)). A dose related increased risk with higher pack years of smoking was observed across all three definitions (which was statistically significant above 1 pack year of smoking) although this was most marked with the NICE definition.

\section{Effect of amount smoked on risk of COPD among female compared with male smokers}

Table 3 shows the risks of COPD by sex and pack years of smoking for each of the three definitions and including an interaction term to assess the susceptibility to smoking between the sexes. With the LLN criteria, once adjusted for age and socioeconomic status, there was no significant difference between the sexes in susceptibility to cigarette smoking at any level, as demonstrated by the lack of significance within the interaction terms. However, with both the GOLD and NICE criteria, the interaction terms produced coefficients of $0.6-0.8$ with 1 or more pack years of smoking, indicating that men had lower risk than women (and conversely women had a higher susceptibility) for the same amount smoked. This was statistically significant for the 1-19 and 20-49 pack years categories although this did not remain significant for those smoking for 50 or more pack years. Repeating the analyses with only current smokers and never smokers reduced the sample size by onethird, showing similar patterns of no interaction between sex and pack year history with the LLN criteria. For the GOLD and NICE criteria, significant interactions remained where smoking levels were reported at 20-49 pack years (data not shown).

\section{DISCUSSION}

Our findings show that both the estimated risk of COPD by sex and susceptibility to smoking between the sexes varies according to the definition used for COPD.

We have shown that in a random sample of the English adult population, the adjusted relative risk (OR) of COPD using the GOLD criteria was overestimated by over twofold by the age of 70 years compared with use of the LLN criteria, and that this was further accentuated with the use of the NICE criteria. These findings are in keeping with reports from a number of population based studies that show that prevalence estimates for COPD vary according to disease definition, and differences are more marked with increasing age. ${ }^{22}{ }^{23}$ Furthermore, use of the GOLD or NICE criteria showed that after adjusting for age and smoking history, men had a $46 \%$ and $30 \%$ increased risk of COPD, respectively, compared with women, whereas no sex difference in risk was observed when the LLN criteria were used. Use of the GOLD fixed ratio of 0.7 has been shown to overestimate COPD prevalence compared with the LLN criteria as 
Table 2 Association between sex, smoking and chronic obstructive pulmonary disease according to GOLD, NICE and LLN criteria* using combined 1995, 1996 and 2001 data on 18504 participants from the Health Survey for England (numbers, percentages and adjusted ORs presented)

\begin{tabular}{|c|c|c|c|c|c|c|}
\hline & \multicolumn{2}{|l|}{ GOLD } & \multicolumn{2}{|l|}{ NICE } & \multicolumn{2}{|l|}{ LLN } \\
\hline & $\overline{\operatorname{COPD}(\mathrm{n}(\%))}$ & Adjusted ORs $(95 \% \mathrm{Cl}) \dagger$ & $\overline{C O P D}(\mathbf{n}(\%))$ & Adjusted ORs $(95 \% \mathrm{Cl}) \dagger$ & $\overline{C O P D}(\mathrm{n}(\%))$ & Adjusted ORs (95\% Cl) $\dagger$ \\
\hline Total with COPD & $3035(16.1)$ & & $1304(7.0)$ & & $1684(9.0)$ & \\
\hline \multicolumn{7}{|l|}{ Age (years) } \\
\hline $50-59$ & $672(13.4)$ & $1.74(1.53$ to 1.98$)$ & $229(4.6)$ & 1.86 (1.47 to 2.33$)$ & $400(8.0)$ & 1.19 (1.02 to 1.38$)$ \\
\hline $60-69$ & $810(19.6)$ & $2.72(2.40$ to 3.09$)$ & $372(9.0)$ & 3.74 (3.03 to 4.62$)$ & $407(9.8)$ & $1.48(1.27$ to 1.73$)$ \\
\hline $70-79$ & $795(26.8)$ & $4.03(3.53$ to 4.60$)$ & $431(14.5)$ & 6.37 (5.16 to 7.86$)$ & $377(12.7)$ & $1.92(1.64$ to 2.25$)$ \\
\hline \multicolumn{7}{|l|}{ Sex } \\
\hline Female & $1252(12.6)$ & 1.00 & $498(5.0)$ & 1.00 & $805(8.1)$ & 1.00 \\
\hline Male & $1783(20.1)$ & $1.46(1.34$ to 1.59$)$ & $806(9.1)$ & $1.30(1.15$ to 1.48$)$ & $879(9.9)$ & $0.96(0.87$ to 1.07$)$ \\
\hline \multicolumn{7}{|c|}{ Smoking (pack years) } \\
\hline Never smoker & $847(10.4)$ & 1.00 & $223(2.8)$ & 1.00 & $427(5.3)$ & 1.00 \\
\hline Ever smoker: $<1$ & $35(9.0)$ & 0.86 (0.60 to 1.24$)$ & $6(1.6)$ & $0.60(0.26$ to 1.36$)$ & $19(4.9)$ & 0.92 (0.57 to 1.50$)$ \\
\hline Non-manual & $1411(13.4)$ & 1.00 & $497(4.7)$ & 1.00 & $773(7.3)$ & 1.00 \\
\hline Manual/other & $1575(19.6)$ & $1.23(1.13$ to 1.33$)$ & $78(9.8)$ & $1.60(1.41$ to 1.80$)$ & $884(11.0)$ & $1.27(1.14$ to 1.41$)$ \\
\hline
\end{tabular}

${ }^{*}$ Global Initiative for Chronic Obstructive Lung Disease (GOLD) criteria ${ }^{18}: \mathrm{FEV}_{1} / \mathrm{FVC}$ ratio $<0.7$; National Institute for Health and Clinical Excellence (NICE) criteria: FEV $/$ FVC $<0.7$ and FEV $<80 \%$ predicted (equivalent to GOLD stage II) ${ }^{19}$; lower limit of normal (LLN) criteria ${ }^{20}{ }^{21}$ : participants with FEV $1 / F V C$ values $>1.645$ SD below the mean reference value. †ORs adjusted for age, sex, pack years of smoking and socioeconomic status.

COPD, chronic obstructive pulmonary disease; FEV $_{1}$, forced expiratory volume in $1 \mathrm{~s}$; FVC, forced vital capacity.

a result of the natural decline in $\mathrm{FEV}_{1} / \mathrm{FVC}$ that occurs with ageing, and sex differences arise because this natural decline starts earlier in men (around age 42 years) compared with women (around age 48 years). ${ }^{13}$ Thus the difference in COPD risk by sex sometimes observed in other studies ${ }^{12} 24$ is likely to be related to the diagnostic criteria used for COPD.
We also found that the risk of COPD by smoking exposure (assessed by pack years) was sensitive to the definition used for COPD. For the same level of exposure, there was a higher risk when using restricted spirometric definitions which were more likely to reflect more severe clinical disease (ie, the NICE criteria) compared with other definitions.

Table 3 Interaction between sex and smoking among participants of the Health Survey for England 1995, 1996 and 2001, by alternative definitions of chronic obstructive pulmonary disease

\begin{tabular}{|c|c|c|c|c|}
\hline & Adjusted $0 R^{*}(95 \% \mathrm{Cl})$ & p Value & $\begin{array}{l}\text { Interaction, male } \times \text { pack years } \\
\text { Adjusted } \mathrm{OR}^{*}(95 \% \mathrm{Cl})\end{array}$ & p Value \\
\hline \multicolumn{5}{|l|}{ LLN criteria† } \\
\hline Sex (male) & 1.03 (0.83 to 1.26$)$ & 0.814 & & \\
\hline Pack years: never smoker & 1.0 & & & \\
\hline Ever smoker: $<1$ & $1.13(0.65$ to 1.96$)$ & 0.677 & 0.50 (0.16 to 1.59$)$ & 0.242 \\
\hline $1-19$ & 1.70 (1.40 to 2.06$)$ & $<0.001$ & 0.87 (0.65 to 1.17$)$ & 0.360 \\
\hline $20-49$ & 2.99 (2.49 to 3.60$)$ & $<0.001$ & 0.97 (0.74 to 1.27 ) & 0.815 \\
\hline $50+$ & 4.27 (3.09 to 5.88$)$ & $<0.001$ & 0.92 (0.62 to 1.37 ) & 0.681 \\
\hline \multicolumn{5}{|l|}{ GOLD criteria $†$} \\
\hline Sex (male) & 1.77 (1.53 to 2.06$)$ & $<0.001$ & & \\
\hline Pack years: never smoker & 1.0 & & & \\
\hline Ever smoker: $<1$ & 1.05 (0.67 to 1.66$)$ & 0.832 & 0.61 (0.28 to 1.31 ) & 0.204 \\
\hline $1-19$ & 1.70 (1.45 to 2.00$)$ & $<0.001$ & $0.75(0.60$ to 0.94$)$ & 0.012 \\
\hline $20-49$ & 2.90 (2.48 to 3.38 ) & $<0.001$ & $0.74(0.60$ to 0.91$)$ & 0.004 \\
\hline $50+$ & $3.79(2.85$ to 5.04$)$ & $<0.001$ & 0.81 (0.58 to 1.13 ) & 0.229 \\
\hline \multicolumn{5}{|l|}{ NICE criteria† } \\
\hline Sex (male) & 1.81 (1.37 to 2.39 ) & $<0.001$ & & \\
\hline Pack years: never smoker & 1.0 & & & \\
\hline Ever smoker: $<1$ & 0.97 (0.39 to 2.42 ) & 0.955 & 0.21 (0.02 to 1.85$)$ & 0.160 \\
\hline $1-19$ & 2.70 (2.06 to 3.53 ) & $<0.05$ & $0.66(0.45$ to 0.96$)$ & 0.028 \\
\hline $20-49$ & 5.58 (4.36 to 7.15$)$ & $<0.001$ & $0.64(0.46$ to 0.90$)$ & 0.011 \\
\hline $50+$ & $8.63(6.00$ to 12.41$)$ & $<0.001$ & $0.74(0.48$ to 1.16$)$ & 0.187 \\
\hline
\end{tabular}


Furthermore, we found an increased susceptibility to COPD among female compared with male smokers only when the GOLD and NICE criteria were used. Men seemed to have a $25-35 \%$ lower risk than women for the same amount smoked. These effects held except for the very highest levels of smoking where even though the point estimate was similar, smaller numbers may have accounted for the lack of statistical significance. With the LLN criteria, there was no difference between the sexes in susceptibility to smoking. Thus in this analysis, use of the GOLD and NICE criteria potentially created a spurious effect.

The results of the lack of effect using the LLN criteria is consistent with the meta-analysis of cross sectional studies published by Vollmer et $a l^{11}$ showing no difference between the sexes in the relationship between amount smoked and adjusted $\mathrm{FEV}_{1}$ values, but at odds with findings from some other longitudinal studies. $^{8}{ }^{25}$ The meta-analysis of these longitudinal studies reported by Gan et $a l^{8}$ shows an overall increased decline in lung function among women smokers compared with men although the authors use $\mathrm{FEV}_{1}$ expressed as per cent predicted to measure lung function, a measure which is also subject to sex bias. The variance of $\mathrm{FEV}_{1}$ around the predicted values is similar for both large and small values, ${ }^{26}$ therefore per cent predicted values will tend to overestimate severity at smaller values (ie, in older people and among women). There are few relevant studies describing COPD (or airflow obstruction) as an outcome among smokers; a 10 year cohort study indicated an increased (but nonsignificant) incidence of COPD in women persistent smokers compared with men with a similar smoking history but had relatively small numbers of cases. ${ }^{10}$ The Framingham offspring cohort study found an increased number of male smokers developing COPD but the authors used GOLD stage II (equivalent to the NICE criteria) to define new cases of COPD. Other studies measuring COPD hospitalisation may be less comparable as there are many reasons why there could be sex differences in hospitalisation rates.

Despite this, the magnitude of the relative risk (OR) for female compared with male smokers using the NICE/GOLD criteria was similar to that observed in a recently conducted meta-analysis of the effects of smoking on risk of coronary artery disease in women compared with men. ${ }^{7}$ Without an agreed single standard for the diagnosis of COPD, it is difficult to conclude whether there is a sex difference in susceptibility to smoking. The LLN criteria are more scientifically derived and if there were no true differences between the sexes in susceptibility to smoking and no true differences between the sexes in their independent risk of COPD, then our data would strengthen the argument for the use of the LLN criteria. At present, without a clear definition of what constitutes COPD, this issue will remain unresolved. Our paper highlights the importance and effects of different COPD definitions on the understanding of the epidemiology of COPD.

\section{Limitations of approach}

Due to the cross sectional nature of this study it is not possible to determine temporal relationships between smoking and COPD and this may have affected our results. The main analyses included ex-smokers; however, we also restricted the analyses to compare current smokers with never smokers. Despite the smaller sample size, significant interactions remained between pack years smoked and sex for the GOLD and NICE criteria for those having smoked 20-49 pack years, thus supporting our argument. Additionally, the HSE, while having advantages of generalisability to the English population, was not designed for this purpose. Although the spirometry was under- taken according to standardised guidance, it may not have been as rigorous as that now recommended by the American Thoracic Society and European Respiratory Society. ${ }^{27}$ Post-bronchodilator measures were not available and the type of equipment used might have made good quality spirometry more difficult to achieve. We excluded participants who reported diagnosed asthma but some participants with airflow obstruction may be undiagnosed asthmatics rather than having COPD. Where spirometric criteria only were used to define COPD, it is likely that this would overestimate the number of true clinical cases. However, these limitations are not likely to affect the comparison of the different spirometric criteria or comparisons between men and women but may have the effect of diluting any overall observed relationships between risk factors and COPD. Detailed data about inhalation were also not available, and this is often cited to explain any sex differences in the effect of smoking. Women are generally held to inhale more ${ }^{28}$ and therefore for the same amount smoked, might be expected to show greater risks than men. However, this is not clearly demonstrated in our analysis with the LLN criteria.

\section{Implications}

The continuing use of the GOLD criteria (and its derivations, such as the NICE criteria) for diagnosis has already been questioned 262930 and our study reinforces this concern. Use of the $\mathrm{FEV}_{1} / \mathrm{FVC}<0.7$ fixed ratio for assigning COPD status overestimates disease among men relative to use of more statistically based criteria for defining disease and also seems to distort the effect of susceptibility to smoking between the sexes. This effect is removed when the LLN method is used because it takes into account the declining $\mathrm{FEV}_{1}$ with age and differences in $\mathrm{FEV}_{1}$ by sex and height observed in the general population. This potential sex bias clearly still exists when using the NICE criteria (equivalent to GOLD stage II).

The natural history of COPD is poorly understood ${ }^{31}$ and research is hampered by the use of unsatisfactory diagnostic criteria. While the use of the LLN criteria may not be the final answer, not least because it relies on reference equations which are not always reliable, it provides a statistically more appropriate measure which acts as a starting point for further work. Future research should include evaluating novel diagnostic measures prospectively as predictors of development of clinical disease.

Our study also questions the notion of women having greater susceptibility to cigarette smoke exposure on developing COPD and it should be ascertained whether the choice of diagnostic criteria also explains observed sex differences in the development and progression of COPD in prospective studies. In the meantime, practitioners should continue to promote smoking prevention and cessation among both sexes.

Acknowledgements The authors are grateful to the UK Data Archive, University of Essex, and the Health Survey for England 1995, 1996, 2001, for providing access to their data.

Contributors REJ, K-BHL, PA, KKC and MM contributed and developed the initial idea. REJ undertook analyses of the HSE. JM advised on the statistics. REJ wrote the paper with input and advice from all authors. All authors take responsibility for the integrity of the data and accuracy of the data analysis.

Funding REJ is funded by a fellowship from the National Institute of Health Research, England.

Competing interests None.

Provenance and peer review Not commissioned; externally peer reviewed.

\section{REFERENCES}

1. Mannino DM, Buist AS. Global burden of COPD: risk factors, prevalence, and future trends. Lancet 2007;370:765-73. 
2. Office for National Statistics and The Health and Social Care Information Centre. Statistics on smoking: England, 2011. http://www.ic.nhs.uk/webfiles/ publications/003 Health Lifestyles/Statistics\%20on\%20Smoking\%202011/ Statistics on Smoking 2011.pdf (accessed 1 Feb 2012).

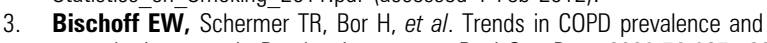
exacerbation rates in Dutch primary care. Br J Gen Pract 2009;59:927-33.

4. Soriano JB, Maier WC, Egger P, et al. Recent trends in physician diagnosed COPD in women and men in the UK. Thorax 2000;55:789-94.

5. van Durme YM, Verhamme KM, Stijnen T, et al. Prevalence, incidence, and lifetime risk for the development of COPD in the elderly: the Rotterdam study. Chest 2009;135:368-77.

6. Prescott E. Commentary: tobacco-related diseases: a gender differential? Int $J$ Epidemiol 2001;30:793-4

7. Huxley RR, Woodward M. Cigarette smoking as a risk factor for coronary heart disease in women compared with men: a systematic review and meta-analysis of prospective cohort studies. Lancet 2011;378:1297-305.

8. Gan W0, Man SF, Postma DS, et al. Female smokers beyond the perimenopausa period are at increased risk of chronic obstructive pulmonary disease: a systematic review and meta-analysis. Respir Res 2006;7:52.

9. Prescott E, Bjerg AM, Andersen PK, et al. Gender difference in smoking effects on lung function and risk of hospitalization for COPD: results from a Danish longitudinal population study. Eur Respir J 1997;10:822-7.

10. Lindberg A, Jonsson AC, Ronmark $E$, et al. Ten-year cumulative incidence of COPD and risk factors for incident disease in a symptomatic cohort. Chest 2005; 127:1544-52.

11. Vollmer WM, Enright PL, Pedula KL, et al. Race and gender differences in the effects of smoking on lung function. Chest 2000;117:764-72.

12. Kohansal R, Martinez-Camblor P, Agusti A, et al. The natural history of chronic airflow obstruction revisited: an analysis of the Framingham offspring cohort. $A m \mathrm{~J}$ Respir Crit Care Med 2009;180:3-10.

13. Swanney MP, Ruppel G, Enright PL, et al. Using the lower limit of normal for the FEV1/FVC ratio reduces the misclassification of airway obstruction. Thorax 2008;12:1046-51.

14. Joint Health Surveys Unit of Social and Community Planning Research and University College London. Health Survey for England, 1995 [Computer file]. 3rd edn. Colchester, Essex: UK Data Archive [distributor], 2001. SN: 3796.

15. Joint Health Surveys Unit of Social and Community Planning Research and University College London. Health Survey for England, 1996 [Computer file]. 3rd edn. Colchester, Essex: UK Data Archive [distributor], 2001. SN: 3886.
16. National Centre for Social Research and University College London. Department of Epidemiology and Public Health. Health Survey for England, 2001 [Computer file]. 2nd edn. Colchester, Essex: UK Data Archive [distributor], 2004. SN: 4628.

17. UK Data Archive. 2009. http://www.data-archive.ac.uk/ (accessed 1 Feb 2012).

18. Global Initiative for COPD Committee. Global Initiative for Chronic Obstructive Lung Disease, Global Strategy for the Diagnosis, Management, and Prevention of Chronic Obstructive Pulmonary Disease. Oregon: GOLD Committee, 2006.

19. The National Collaborating Centre for Chronic Conditions. Chronic obstructive pulmonary disease. National clinical guideline on management of chronic obstructive pulmonary disease in adults in primary and secondary care. Thorax 2004;59:1-232.

20. Pellegrino R, Viegi G, Brusasco V, et al. Interpretative strategies for lung function tests. Eur Respir J 2005;26:948-68.

21. Quanjer PH, Tammeling GJ, Cotes JE, et al. Lung volumes and forced ventilatory flows. Report Working Party Standardization of Lung Function Tests, European Community for Steel and Coal. Official Statement of the European Respiratory Society. Eur Respir J 1993;16:5-40.

22. Jordan RE, Lam KB, Cheng KK, et al. Case finding for chronic obstructive pulmonary disease: a model for optimizing a targeted approach. Thorax 2010;65:492-8.

23. Vollmer WM, Gislason T, Burney $\mathrm{P}$, et al. Comparison of spirometry criteria for the diagnosis of COPD: results from the BOLD study. Eur Respir J 2009:34:588-97.

24. de Torres JP, Campo A, Casanova C, et al. Gender and chronic obstructive pulmonary disease in high-risk smokers. Respiration 2006;73:306-10.

25. $\mathbf{X u} \mathbf{X}, \mathrm{Li}$ B, Wang L. Gender difference in smoking effects on adult pulmonary function. Eur Respir J 1994;7:477-83.

26. Culver B. Interpretation of spirometry: we can do better than the GOLD standard. Respir Care 2006;51:719-20.

27. Miller MR, Hankinson J, Brusasco V, et al. Standardisation of spirometry. Eur Respir J 2005:26:319-38.

28. Taylor DR, Reid WD, Pare PD, et al. Cigarette smoke inhalation patterns and bronchial reactivity. Thorax 1988;43:65-70.

29. Miller MR, Pedersen OF, Pellegrino R, et al. Debating the definition of airflow obstruction: time to move on? Eur Respir J 2009;34:527-8.

30. Pellegrino R, Brusasco V, Viegi G, et al. Definition of COPD: based on evidence or opinion? Eur Respir J 2008;31:681-2.

31. Mannino DM, Watt G, Hole D, et al. The natural history of chronic obstructive pulmonary disease. Eur Respir J 2006;27:627-43.

\section{Thorax alerts}

Sign up for our electronic table of contents alerts and you will never miss new issues of Thorax when published online. Stay ahead and up to date by visiting thorax.bmj.com. 